DRUG DISCOVERY AND RESISTANCE

\title{
Morphological changes and differentially expressed efflux pump genes in Mycobacterium tuberculosis exposed to a rifampicin and verapamil combination
}

\author{
Katiany R. Caleffi-Ferracioli ${ }^{\text {a, b}}$, Renata Claro R. Amaral ${ }^{\text {b }}$, Fernanda O. Demitto ${ }^{\text {, }}$, \\ Flaviane G. Maltempe ${ }^{\mathrm{b}}$, Pedro Henrique Canezin ${ }^{\mathrm{b}}$, Regiane B.L. Scodro ${ }^{\mathrm{b}}$, \\ Celso V. Nakamura ${ }^{\mathrm{c}}$, Clarice Queico F. Leite ${ }^{\mathrm{d}}$, Vera Lúcia D. Siqueira ${ }^{\mathrm{b}}$, \\ Rosilene F. Cardoso a, b, * \\ a Postgraduate Program in Health Science, State University of Maringa, Parana, Brazil \\ b Laboratory of Medical Bacteriology, Department of Clinical Analysis and Biomedicine, State University of Maringa, Parana, Brazil \\ ${ }^{\mathrm{c}}$ Department of Basic Health Sciences, State University of Maringa, Parana, Brazil \\ ${ }^{\mathrm{d}}$ School of Pharmaceutical Sciences, Department of Biological Sciences, Paulista State University, Araraquara, Sao Paulo, Brazil
}

\section{A R T I C L E I N F O}

\section{Article history:}

Received 15 September 2014

Received in revised form

29 December 2015

Accepted 30 December 2015

\section{Keywords:}

Mycobacterium tuberculosis

Efflux pump

Morphological changes

Gene expression

Drug combinations

\begin{abstract}
S U M M A R Y
The aim of the present study was to (i) evaluate the in vitro action of rifampicin (RIF), ethambutol or isoniazid with efflux pumps inhibitors (EPIs) in Mycobacterium tuberculosis (Mtb) $\mathrm{H}_{37} \mathrm{Rv}$ and (ii) evaluate the morphological and efflux pumps (EPs) transcriptional changes by the action of rifampicin + verapamil combination (RIF + VP). The minimal inhibitory concentration and synergic effect of drug combinations were determined by Resazurin Microtiter Plate Assay and Resazurin Drugs Combination Microtiter Assay, respectively. VP showed greater capacity of ethidium bromide accumulation and RIF + VP had the lower fractional inhibitory concentration index. The RIF + VP exerted a similar reduction of viable cell counts to RIF by time-kill curve, but decreases in the expression of EPs genes were observed by Real time PCR at $72 \mathrm{~h}$ of RIF + VP exposure. Accumulative morphological changes (wrinkled and rounding) caused by each drug were observed by scanning electron microscopy after RIF + VP exposure. The downexpression of EPs related genes exposed to RIF + VP, suggest an effective inhibitory activity of VP in $M t b \mathrm{H}_{37} \mathrm{Rv}$. The role of EPs and the use of EPIs open up a powerful approach and the RIF + VP combination should be studied in Mtb more thoroughly.
\end{abstract}

๑) 2016 Elsevier Ltd. All rights reserved.

\section{Introduction}

Tuberculosis (TB) is responsible for 8.6 million new cases and accounted for 1.3 million deaths in 2012, especially in poor countries [1]. The emergence of multidrug-resistant (MDR) and extensively drug-resistant (XDR) Mycobacterium tuberculosis (Mtb) has become a major public health concern worldwide [2].

$M t b$ are naturally resistant to commonly used drugs because of the slow uptake of drugs across the highly hydrophobic

* Corresponding author. Laboratório de Bacteriologia Médica, Universidade Estadual de Maringá, Avenida Colombo, 5790, 87020-900 Maringá, Paraná, Brazil. Tel.: +55 443011 5375; fax: +55 4430114797 .

E-mail address: rfressatticardoso@gmail.com (R.F. Cardoso). mycobacterial cell envelop [3]. In addition to the unique structure of the bacteria, mutations in target genes, which encode proteins involved in the drug metabolism, are known to be an important mechanism of resistance. However, explaining the resistance to anti-TB drugs, without mutations in known target genes, has not yet been possible. Recently, this resistance has been attributed to active drug efflux mechanism.

Bacterial efflux pumps (EPs) are membrane proteins that are capable of actively transporting a broad range of drugs $[3,4]$. The constitutive or inducible expression of EPs in response to treatment contributes to a decrease in the intracellular concentration of antiTB drugs and thus resistance by the bacillus [5,6].

$M t b$ has a large number of putative drug EPs genes [2]. Some EPs have been described and well characterized in $M t b$ as belonging to the adenosine triphosphate binding cassette (ABC), major 
facilitator superfamily (MFS), resistance nodulation division (RND), and small multidrug resistance (SMR) families [2,3,7]. Some EPs have been reported to play a role in resistance to anti-TB drugs, such as rifampicin (RIF), ethambutol (EMB) and isoniazid (INH) $[5,8,9]$.

Efflux pump inhibitors (EPIs) have been tested in combinations with anti-TB drugs to increase the intracellular concentration and restore the activity of the drugs. Some EPIs, affect transmembrane electrochemical potential and others are calcium channel antagonist such as carbonyl cyanide $m$-chlorophenyl-hydrazone (CCCP) and verapamil (VP), respectively [10]. However, the mechanisms involved in the induction and regulation of EPs are not yet fully understood [2].

Studies in vitro [11] and in vivo [12] have shown the applicability of EPIs, used as antiarrhythmic, antihypertensive, antiulcer, and antiemetic [10], in restoring the susceptibility of Mtb MDR clinical isolates to anti-TB drugs.

EPs-mediated resistance has become important, once help the mycobacteria survive under presence of the anti-TB drugs, until relevant mutations emerge in the genome [11]. In this sense, the use of EPIs, as an adjunctive therapy, in attempt to restore the anti-TB drugs activity or accelerate the treatment, seems to be of interest [12]. For this, the knowledge of the effect of combination EPIs and anti-TB drugs, as well as, the influence of this combination in morphology and gene expression in the bacillus could help us to understand the advantages of this therapeutic approach.

The aim of the present study was to $(i)$ evaluate the in vitro action of RIF, EMB or INH with EPIs (CCCP or VP) combinations in $M t b \mathrm{H}_{37} \mathrm{Rv}$ and (ii) evaluate possible morphological and EPs transcriptional changes in $M t b \mathrm{H}_{37} \mathrm{Rv}$ exposed to the anti-TB drug and EPI combination, which had the lower fractional inhibitory concentration index (FICI) against the bacillus.

\section{Materials and methods}

\subsection{Bacterial culture}

M. tuberculosis $\mathrm{H}_{37} \mathrm{Rv}$ (ATCC 27294), was used throughout the study. Bacterial cells were grown at $35-37{ }^{\circ} \mathrm{C}$ for 15 days in Middlebrook 7H9 medium (Difco Laboratories, Detroit, MI, USA) supplemented with $10 \%(\mathrm{v} / \mathrm{v})$ oleic acid-bovine serum albumin-dextrose catalase enrichment (OADC, BBL/Becton-Dickinson, Sparks, MD, USA), with the addition of $0.2 \%$ glycerol $(\mathrm{v} / \mathrm{v})$ and $0.025 \%$ Tween $80(\mathrm{v} / \mathrm{v})$.

\subsection{Anti-TB drugs and efflux pump inhibitors}

All drugs were provided by Sigma (St. Louis, MO, USA). INH, EMB, and VP were prepared in distillate water, CCCP in dimethyl sulfoxide (DMSO; Synth, Diadema/SP, Brazil) and RIF in methanol:water $(1: 10, v / v)$. Further dilutions were prepared in OADCsupplemented Middlebrook 7H9 with the following concentration ranges: RIF $(0.0005-0.25 \mu \mathrm{g} / \mathrm{mL})$, INH $(0.0009-0.25 \mu \mathrm{g} / \mathrm{mL})$, EMB $(0.125-32 \mu \mathrm{g} / \mathrm{mL}), \quad$ CCCP $(0.39-100 \mu \mathrm{g} / \mathrm{mL})$, and VP $(3.90-1000 \mu \mathrm{g} / \mathrm{mL})$. The final DMSO and methanol concentrations had no effect on $M t b$ growth.

\subsection{Determination of MIC and checkerboard assay}

The MIC was determined in triplicate for anti-TB drugs and EPIs using the Resazurin Microtiter Assay Plate (REMA) as described by Palomino et al. [13].

The interactions between anti-TB drugs and EPIs were evaluated in triplicate using the Resazurin Drugs Combination Microtiter
Assay (REDCA) as described previously by Caleffi-Ferracioli et al. [14]. The fractional inhibitory concentration index (FICI) was used to evaluate the drugs combination and the results were interpreted as synergism $(\mathrm{FICI} \leq 0.50)$, indifference/additive ( $\mathrm{FICI}>0.50-4)$ or antagonism $(\mathrm{FICI}>4)[15]$.

\subsection{Accumulation of ethidium bromide}

The ethidium bromide (EtBr) MIC was determined by the REMA [13] and EtBr accumulation in Mtb cells was assessed by fluorometry [6,16]. Mtb $\mathrm{H}_{37} \mathrm{Rv}$ was grown in 7H9-OADC medium at $35-37^{\circ} \mathrm{C}$ until an optical density at $600 \mathrm{~nm}\left(\mathrm{OD}_{600}\right)$ of $0.6-0.8$. The culture was centrifuged at $2880 \times \mathrm{g}$ for $10 \mathrm{~min}$. The pellet was washed and resuspended in phosphate-buffered saline (PBS; $\mathrm{pH}$ 7.4). After adjusting the $\mathrm{OD}_{600}$ to 0.4 with $\mathrm{PBS}$ (with $0.05 \%$ Tween 80, Synth, Diadema/SP, Brazil), $100 \mu \mathrm{L}$ aliquots of bacterial suspension were transferred to microplate wells that contained $0.25 \mu \mathrm{g} / \mathrm{mL} \mathrm{EtBr}(0.5 \times \mathrm{MIC})[16]$. Ten microliters of CCCP and VP $(0.5 \times \mathrm{MIC})$ were added to the corresponding well in the microplate and incubated at $25^{\circ} \mathrm{C}$ for $15 \mathrm{~min}$. Fluorescence was determined in the absence of CCCP and VP as a reference assay. Relative fluorescence to EtBr-loaded cells was acquired every $51 \mathrm{~s}$ for $60 \mathrm{~min}$ at $37{ }^{\circ} \mathrm{C}$ in a VICTOR ${ }^{2}$ D fluorometer (PerkinElmer, Santa Clara, CA, USA) using $530 / 25 \mathrm{~nm}$ as the excitation wavelengths and 590/ $20 \mathrm{~nm}$ as the detection wavelengths, respectively [6]. The relative fluorescence values were obtained by normalizing the data against the background fluorescence of EtBr. The relative final fluorescence (RFF) was determined using the formula $\left(R_{\text {assay }}-R F_{r e f}\right) / R F_{r e f}$, where $\mathrm{RF}_{\text {assay }}$ is the relative fluorescence at the last time point (minute 60) of the EtBr accumulation assay with EPIs, and $\mathrm{RF}_{\text {ref }}$ is the relative fluorescence at the last time point of the EtBr accumulation assay without EPIs [6].

\subsection{Time-kill curve assay}

The time-kill curve was performed with the drug combination that showed the lowest FICI by REDCA using the $0.5 \times$ MIC of each drug. Five millilitres of $M t b \mathrm{H}_{37} \mathrm{Rv}\left(7.5 \times 10^{6} \mathrm{CFU}\right.$ (colony-forming unit) $/ \mathrm{mL}$, range $6-8 \times 10^{6}$ ) in OADC-supplemented Middlebrook 7H9 was exposed to RIF, VP and to RIF + VP combination, in shaking at $96 \mathrm{rpm}$ at $35-37{ }^{\circ} \mathrm{C}$. A growth control without drugs was included. Aliquots $(0.1 \mathrm{~mL})$ were removed at $0,1,2,3,5,7$ days, provided that mycobacterial suspensions did not show visible aggregation, and serially diluted $\left(10^{-1}, 10^{-3}\right.$ and $\left.10^{-5}\right)$ in sterile saline to avoid RIF and VP carry-over. Afterward, $20 \mu \mathrm{L}$ of each dilution was seeded on OADC-supplemented Middlebrook 7H11 (Difco Laboratories, Detroit, MI, USA). The plates were incubated at $35-37^{\circ} \mathrm{C}$ for 21 days, and the colonies were counted. The time-kill curves were performed in two time independent experiments. Synergy was defined as a decrease of $\geq 2 \log _{10}$ CFU/mL compared with the most active single drug [17].

\subsection{Scanning electron microscopy}

The RIF and VP combination that showed the lowest FICI, by REDCA, was selected for scanning electron microscopy (SEM). Mtb $\mathrm{H}_{37} \mathrm{Rv}$ was exposed to the $0.5 \times$ MIC of VP, RIF, and RIF + VP for 16 and $72 \mathrm{~h}$ at $35-37^{\circ} \mathrm{C}$. After drug exposure, the cells were fixed with $2.5 \%$ glutaraldehyde (Sigma) in $0.1 \mathrm{M}$ cacodylate buffer (Electron Microscopy Science, Hatfield, PA, USA) for at least $2 \mathrm{~h}$ at $4{ }^{\circ} \mathrm{C}$. The treated cells were placed on a glass support with poly-L-lysine (Sigma), dehydrated in graded ethanol, critical-point-dried in $\mathrm{CO}_{2}$, coated with gold, and observed in a Shimadzu SS-550 (Kyoto, Japan) scanning electron microscope. An average of 20-30 microscopic fields, in each sample, were selected by random scanning 
and photographed. SEM was performed in duplicate with different cultures to ensure reproducibility of the obtained data.

\subsection{Efflux pump gene expression}

Mtb $\mathrm{H}_{37} \mathrm{Rv}$ was exposed to VP, RIF, and RIF + VP $(0.5 \times \mathrm{MIC})$ for 16 and $72 \mathrm{~h}$ at $35-37^{\circ} \mathrm{C}$. Total RNA from growth was extracted in two time-independent experiments and purified using RNeasy Mini Kit Plus (Qiagen Biotechnology, Valencia, CA, USA) according to the manufacturer's instructions. Quantification/purity and quality assessments were performed with a Qubit 2.0 fluorometer (Invitrogen, Carlsbad, CA, USA). RNA quality (RIN > Qubit 2.0 fluorometer9.0) was assessed using an Agilent BioAnalyzer. Contaminating DNA was removed by prior treatment with RNasefree DNase I (Invitrogen, Carlsbad, CA, USA).

First-strand cDNA was synthesized with random primer (Invitrogen, Carlsbad, CA, USA) and qPCR was performed using SYBR green PCR master mix (Applied Biosystems, Foster City, CA, USA). EPs specific primers (Promega, Madison, WI, USA) are listed in Table 1. Melting curves for reactions were assessed, and samples were run in triplicate. The 16S RNA (rrs) gene was used to normalize all reactions. Negative control was performed in all experiments. A reference assay was conducted in the absence of drugs. The relative quantification of target gene expression was calculated by the $2^{-\Delta \Delta C T}$ method [18]. The data analysis was performed using a oneway test with SAS 9.0 software (SAS OnlineDoc 9, SAS Institute, Cary, NC, USA), followed by the Tukey post hoc test $(p<0.01$ were considered significant).

\section{Results}

The MICs for RIF, EMB, INH, CCCP, and VP were 0.004, 2.0, 0.03, 3.125 , and $125 \mu \mathrm{g} / \mathrm{mL}$, respectively. The FICIs observed by REDCA were 0.75 and 1.5 for RIF + VP and RIF + CCCP, respectively. For the other drug combinations, the FICI was 2 (Table 2).

The $0.25 \mu \mathrm{g} / \mathrm{mL}(0.5 \times \mathrm{MIC})$ of EtBr did not affect cell viability (influx-efflux in equilibrium). EtBr efflux was inhibited by VP and CCCP (Figure 1). The RFF was 0.544 for VP and 0.154 for CCCP.
Time-kill curves were performed for VP (EPI that showed the largest intracellular EtBr accumulation), RIF + VP (combination that showed the lowest FICI by REDCA), and RIF (drug of choice) (Figure 2). No decrease $\geq 2 \log _{10} \mathrm{CFU} / \mathrm{mL}$ was observed with $M t b$ $\mathrm{H}_{37} \mathrm{Rv}$ exposed to RIF + VP compared with RIF alone.

Figure 3.1 $\mathrm{a}$ and $\mathrm{b}$ shows the appearance of drug-unexposed cells at 16 and $72 \mathrm{~h}$, respectively, with dimorphic rod-shaped cells, a smooth surface, and typical cord formation. Figure 3.2, 3.3, and 3.4 show the aspects of treated cells. Wrinkled and rounding cells were observed in $M t b \mathrm{H}_{37} \mathrm{Rv}$ exposed to RIF and VP, respectively, mainly at $72 \mathrm{~h}$. The effect of RIF on cell morphology was less evident (Figure 3.2a and b) compared with cells exposed to VP (Figure 3.3a and $b$ ). A summation of effects caused by RIF and VP exposure was observed with the RIF + VP, with a larger intensity at $72 \mathrm{~h}$ (Figure 3.4a and b).

Figure 4 shows the relative quantification of the transcript levels for 12 selected EP genes in $M t b \mathrm{H}_{37} \mathrm{Rv}$ exposed to RIF, VP, and RIF + VP for 16 h (Figure 4a) and 72 h (Figure 4b). After 16 h of drug exposure, a significant difference in relative expression $(p \leq 0.01)$ was detected in six EP genes ( $R v 1458, R v 1218, R v 1819, R v 2846$, $R v 1258$ and $R v 1410)$ for RIF, nine (Rv1456, $R v 1458, R v 1218, R v 1457$, $R v 1819, R v 2846, R v 1258, R v 2942$ and $R v 1410)$ for VP, and seven (Rv1458, Rv1218, Rv1457, Rv1819, Rv1258, Rv1217 and Rv2459) for RIF + VP. At $72 \mathrm{~h}$, a significant difference in the relative expression $(p \leq 0.01)$ for the EP genes was also observed in ten $(R v 1456$, Rv3065, Rv1458, Rv1457, Rv2846, Rv1258, Rv2942, Rv1217, Rv2459 and $R v 1410)$ for RIF, three ( $R v 3065, R v 1457$, and $R v 1410)$ for VP, and four ( $R v 1457, R v 2846, R v 1258$ and $R v 2942)$ for RIF + VP.

Downregulation of relative expression was observed in most of the studied EP genes at $16 \mathrm{~h}$ of VP exposure. At $72 \mathrm{~h}$, upregulation of most of the studied EP genes was observed with RIF. The RIF + VP showed lower EP gene expression (with the exception of Rv2846) at 72 h compared with RIF.

\section{Discussion}

Evidence suggests the involvement of EPs to contribute to resistance to anti-TB drugs in $M t b$ and the use of EPIs may restore

Table 1

Primers used to assess relative efflux pump gene expression by qPCR.

\begin{tabular}{|c|c|c|c|c|}
\hline Efflux pump gene & Transporter family & Sequences $\left(5^{\prime}-3^{\prime}\right)$ & Amplicon size (bp) & Reference \\
\hline Rv2942 & RND & $\begin{array}{l}\text { Fw- TACCCAAGCTGGAAACAA } \\
\text { Rv- CCGTCAGAATAGAGGAACAG }\end{array}$ & 214 & {$[28]$} \\
\hline Rv3065 & SMR & $\begin{array}{l}\text { Fw- AACCAGCCTGCTCAAAAG } \\
\text { Rv- CAACCACCTTCATCACAGA }\end{array}$ & 221 & [28] \\
\hline Rv2846 & MFS & $\begin{array}{l}\text { F- ATGGTAATGCCTGACATCC } \\
\text { Rv- CTACGGGAAACCAACAAAG }\end{array}$ & 131 & [28] \\
\hline Rv1410c & MFS & $\begin{array}{l}\text { Fw- AGTGGGAAATAAGCCAGTAA } \\
\text { R- TGGTTGATGTCGAGCTGT }\end{array}$ & 198 & [28] \\
\hline Rv1258c & MFS & $\begin{array}{l}\text { Fw- AGTTATAGATCG GCTGGATG } \\
\text { Rv- GTGCTGTTCCCGAAATAC }\end{array}$ & 268 & [28] \\
\hline Rv2459 & MFS & $\begin{array}{l}\text { Fw- CATCTTCATGGTGTT CGT G } \\
\text { Rv- CGGTAGCACACAGACAATAG }\end{array}$ & 232 & [27] \\
\hline Rv1456c & $\mathrm{ABC}$ & $\begin{array}{l}\text { Fw- GAGTCGCACCAGAATCGC } \\
\text { Rv- TCGCTGTTGGTTGCCTAC }\end{array}$ & 90 & {$[25]$} \\
\hline Rv1457c & $\mathrm{ABC}$ & $\begin{array}{l}\text { Fw- GTAGCACCGAGTCGTTTG } \\
\text { Rv- ATCTCCACCGCATTCACC }\end{array}$ & 80 & [25] \\
\hline Rv1458c & $\mathrm{ABC}$ & $\begin{array}{l}\text { Fw- CAGTCCAAGTACCTCAATG } \\
\text { Rv- GCGATACGGGTCAATAAC }\end{array}$ & 163 & {$[25]$} \\
\hline Rv1218c & $\mathrm{ABC}$ & $\begin{array}{l}\text { Fw- CCGCAAGGCGTCTAGTGAA } \\
\text { Rv- TGGACCCGTTGATGGAAAA }\end{array}$ & 173 & [23] \\
\hline Rv1217c & $\mathrm{ABC}$ & $\begin{array}{l}\text { Fw- CGGTGAGGTTGGCGTAG } \\
\text { Rv- CGGTCGGAATCTGGAAA }\end{array}$ & 150 & [23] \\
\hline Rv1819c & $\mathrm{ABC}$ & $\begin{array}{l}\text { Fw- CGGTGATTTCTTTCACAGC } \\
\text { Rv- CCGACAGATTCCATCCATT }\end{array}$ & 351 & [23] \\
\hline 16s RNA & & $\begin{array}{l}\text { Fw- CAAGGCTAAAACTCAAAGGA } \\
\text { Rv- GGACTTAACCCAACATCTCA }\end{array}$ & 197 & [28] \\
\hline
\end{tabular}


Table 2

MIC and FICI values for the classical drugs, efflux pump inhibitors and drug combinations in Mycobacterium tuberculosis $\mathrm{H}_{37} \mathrm{Rv}$.

\begin{tabular}{|c|c|c|c|c|c|c|c|}
\hline \multirow[t]{2}{*}{ Drugs combination } & \multicolumn{5}{|c|}{$\mathrm{MIC}(\mu \mathrm{g} / \mathrm{mL})$} & \multicolumn{2}{|l|}{ REDCA } \\
\hline & INH & EMB & RIF & СCCP & VP & MICs $(\mu \mathrm{g} / \mathrm{mL})$ drug/inhibitor & FICI \\
\hline $\mathrm{RIF}+\mathrm{VP}$ & - & - & 0.004 & - & 125 & $0.001 / 62.5$ & 0.75 \\
\hline $\mathrm{RIF}+\mathrm{CCCP}$ & - & - & 0.004 & 3.125 & - & $0.004 / 1.56$ & 1.5 \\
\hline $\mathrm{EMB}+\mathrm{VP}$ & - & 2 & - & - & 125 & $2 / 125$ & 2 \\
\hline $\mathrm{EMB}+\mathrm{CCCP}$ & - & 2 & - & 3.125 & - & $2 / 3.125$ & 2 \\
\hline $\mathrm{INH}+\mathrm{VP}$ & 0.03 & - & - & - & 125 & $0.03 / 125$ & 2 \\
\hline $\mathrm{INH}+\mathrm{CCCP}$ & 0.03 & - & - & 3.125 & - & $0.03 / 3.125$ & 2 \\
\hline
\end{tabular}

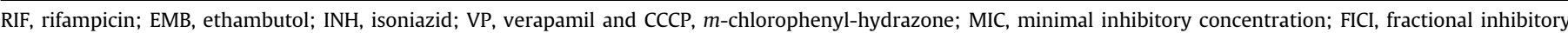
concentration index; REDCA, resazurin drugs combination microtiter assay; -, not performed.

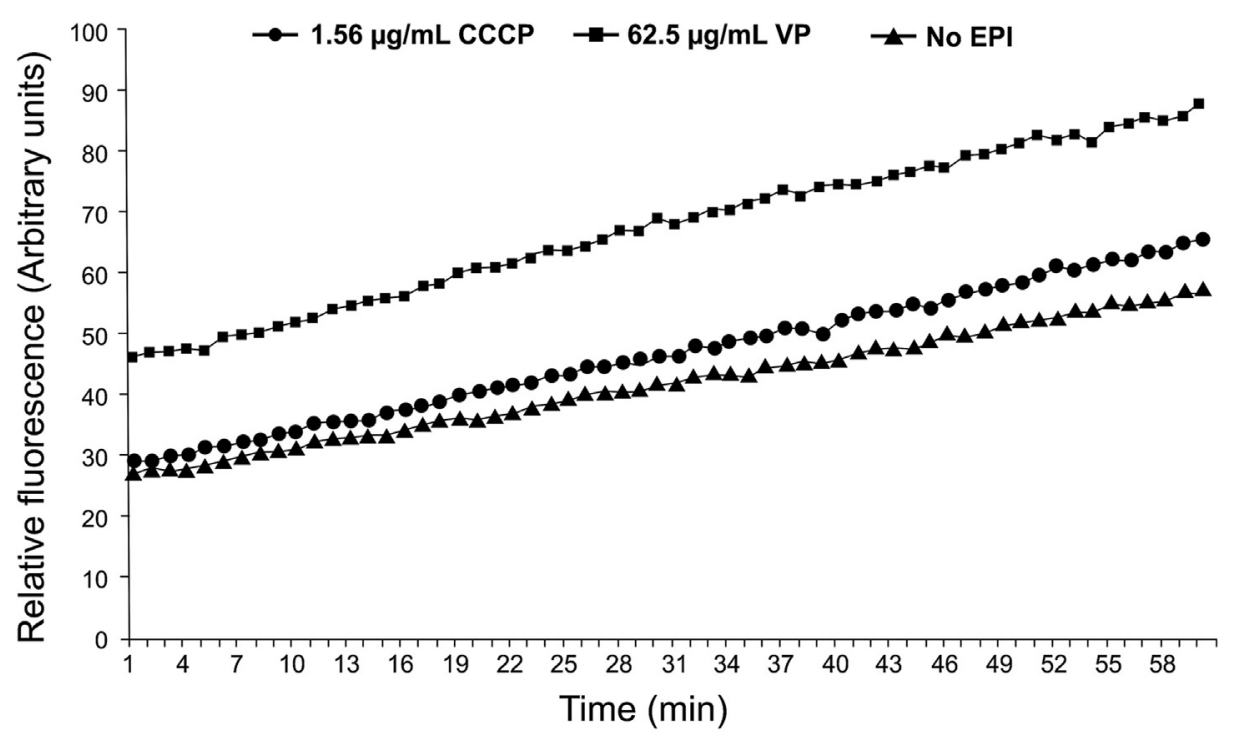

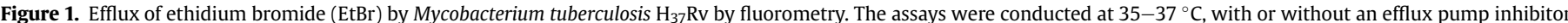

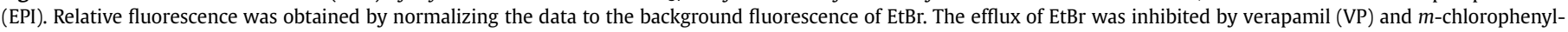
hydrazone $(\mathrm{CCCP})$ at $0.5 \times$ MIC. Relative final fluorescence $(\mathrm{RFF})$ was calculated for each EPI

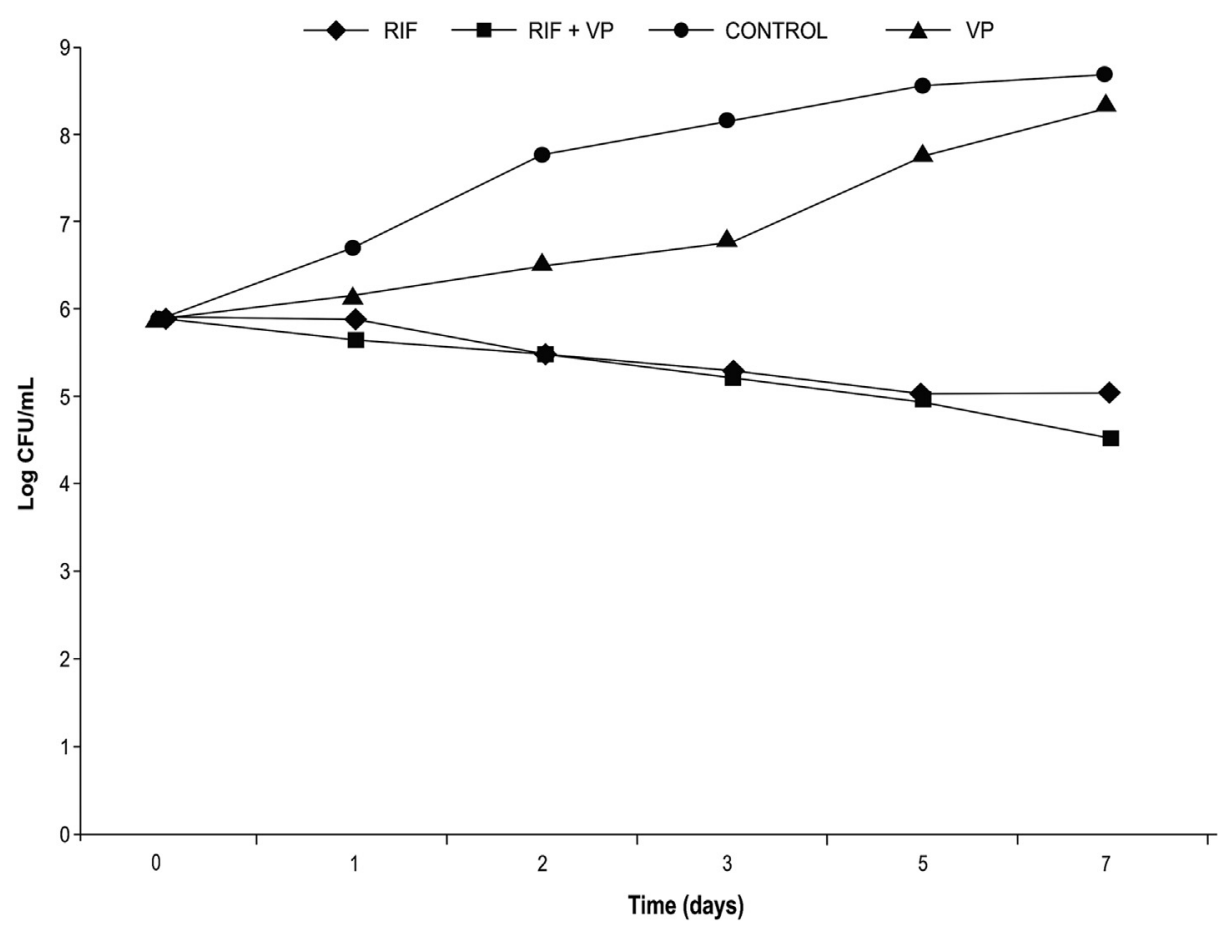

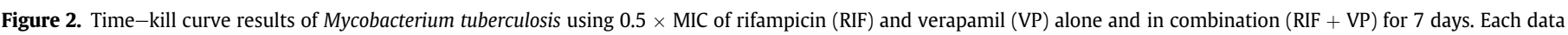
point (days $0,1,2,3,5$, and 7 ) represents the mean number of viable bacterial cell counts in duplicate experiments. 

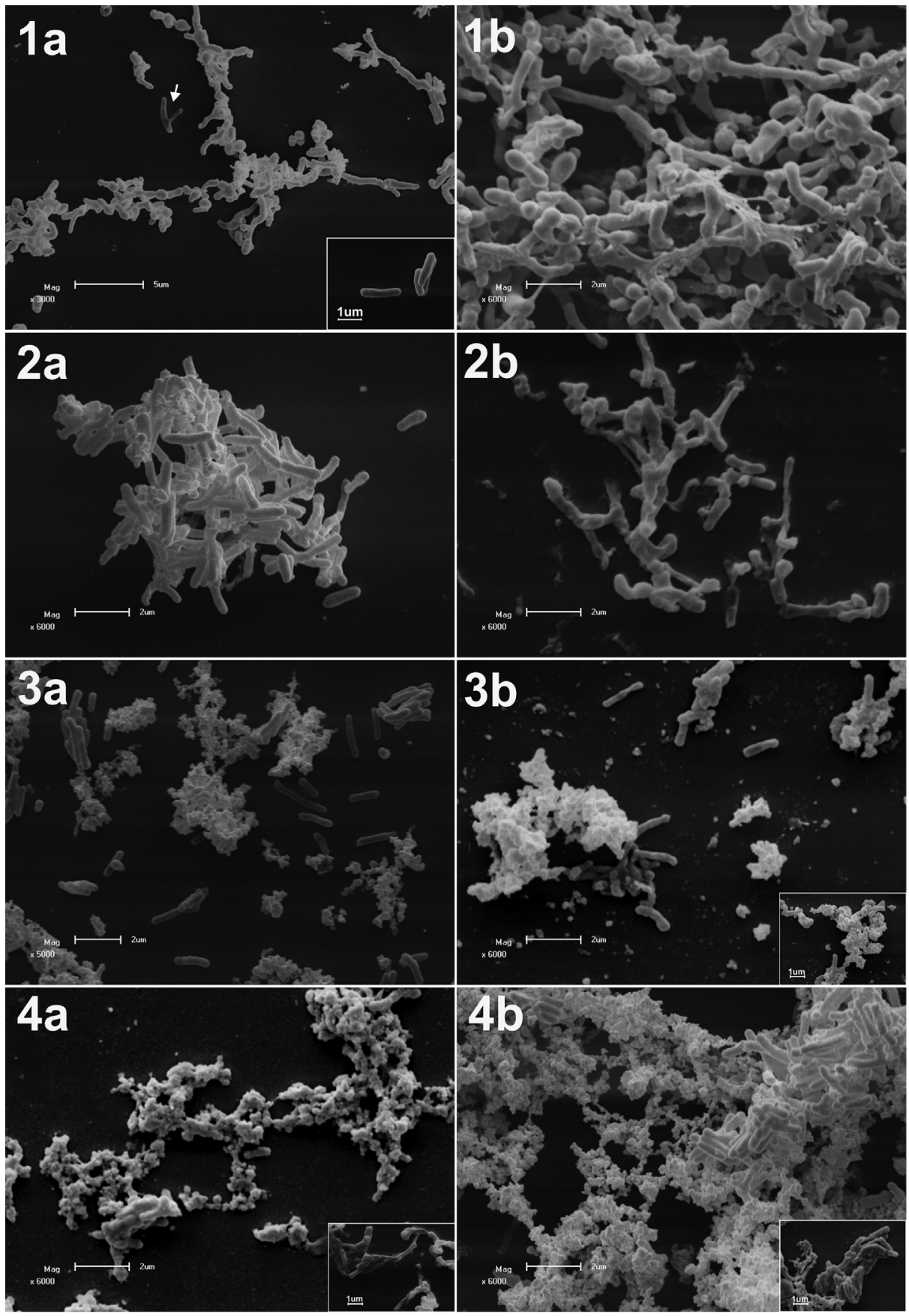

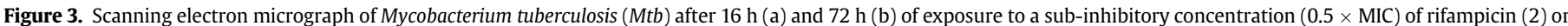

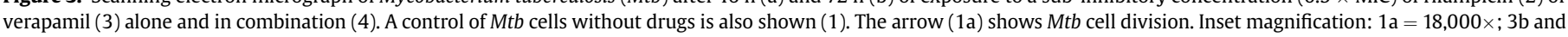
$4 a-b=10,000 \times$

drug susceptibility [11]. However, the effect of these combinations on the morphology and expression of particular genes is unclear. In the present study, the activity of RIF, INH, or EMB combined with CCCP or VP were evaluated in $M t b \mathrm{H}_{37} \mathrm{Rv}$.

Although no synergistic effect was revealed between anti-TB drugs and CCCP or VP, the RIF + VP combination ( FICI $=0.75$ ) showed a considerable reduction on the MIC. By EtBr accumulation assay, VP showed a greater capacity of accumulation $(\mathrm{RFF}=0.544)$, indicating better EPs inhibition compared to CCCP $(\mathrm{RFF}=0.154)$.

The above result encouraged us to carry out time-kill curve using RIF + VP at subinhibitory concentration. Although, synergistic effect of the RIF + VP combination was not observed
( $<2 \log _{10} \mathrm{CFU} / \mathrm{mL}$ ), an effect on MIC decreases was confirmed by time kill curve, mainly with seven days of exposure. The activity of RIF in reducing viable cell counts was time-dependent, which is consistent with the de Steenwinkel et al. [19].

Most SEM studies in Mtb, were performed in the 1950s and 1960s, with lack of high resolution compared to modern standards [20]. To our knowledge, no morphological study, by SEM, of Mtb after RIF and VP exposure has been published to date. The exposure times (16 and $72 \mathrm{~h}$ ) were based on the Mtb generation time and activity in reducing viable cell counts in time-kill curve. Subinhibitory drug concentrations were used to evaluate the primary morphological changes and a true transcriptional profile related to 

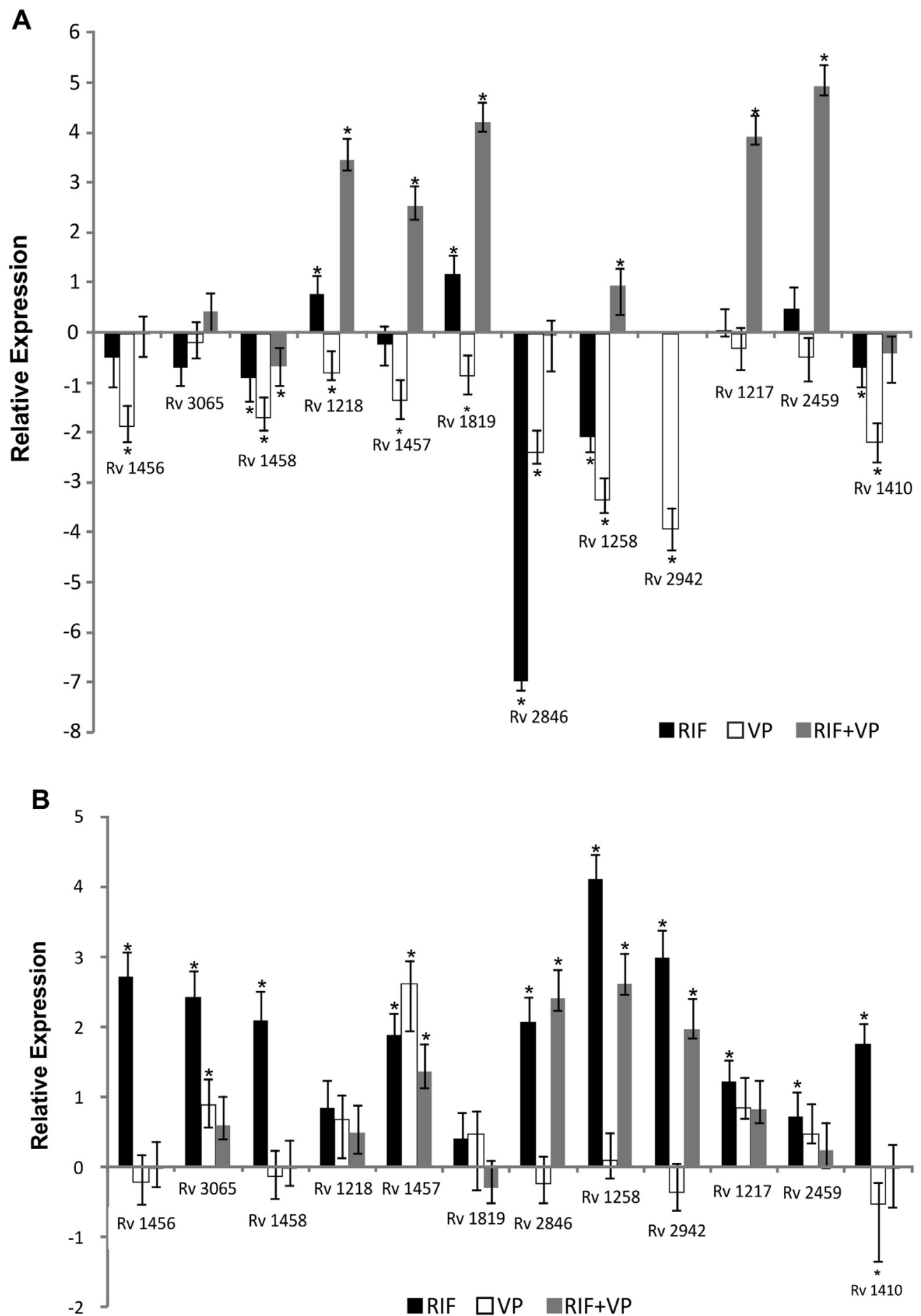

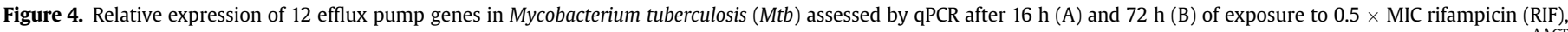

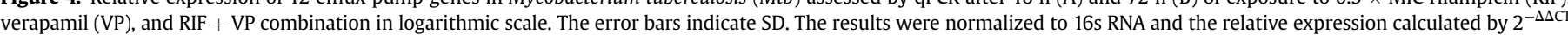
method. ${ }^{*} p<0.001$, compared with $M t b$ control growth in the absence of the drugs.

exposure to the RIF + VP and reducing the effect of stress on the bacteria.

The morphology of $M t b \mathrm{H}_{37} \mathrm{Rv}$, not exposed to drugs, showed transient branching structures of cell division (Figure 3.1a) as observed by Dahl [21]. The effect of RIF on the morphology was more evident at $72 \mathrm{~h}$, which is consistent with lower viable cell counts at 16 h by time-kill curve. Interestingly, with VP exposure, induction of cell rounding was observed, but viable cell counts were not appreciably affected at $72 \mathrm{~h}$.
Cell wrinkling was observed in RIF exposure, that is consistent with the presently known mechanism of action of the drug. The main biotarget of RIF is the $\beta$ subunit of DNA-dependent RNA polymerase, encoded by the $r p o B$ gene, which suppresses the transcription process [8]. The morphological changes (i.e., cell rounding) observed in VP exposure agree with its action on the cell wall. Verapamil is a well-known calcium channel antagonist and inhibitor of human membrane protein P-glycoprotein (P-gp) that is responsible for the efflux of a wide range of drugs [10]. 
Twelve EPs genes from the ABC [10,22], MFS [4,23], RND [7], and SMR [6] families, which have been associated with resistance in $M t b$, were chosen for conducting the study.

The best EPs inhibitory effect by VP was observed at $16 \mathrm{~h}$. This is consistent with the time-kill curve, in which an initial bacillus growth inhibition was observed. After this time, bacillus restored the growth, notably VP exhibited bacteriostatic effect.

For RIF, overexpression of most of the studied EPs genes was observed at $72 \mathrm{~h}$. A parallel may be observed with the time-kill curve where an adaptation of the bacillus to RIF started at this time in an attempt to restore their growth. Notably, RIF is a hydrophobic drug and may enter the cell by diffusion through the hydrophobic bilayer; thus, the active EPs extrude the drug out of the cell, allowing for the typical drug tolerance phenomenon.

The observed expression changes over RIF exposure time are consistent with Calgin et al. [3], who postulated that an increase in EPs expression in $M t b$ clinical isolates during treatment can drive constitutive or inducible EPs expression and lead to an increase in the MICs of anti-TB drugs and render bacillus resistant.

Resistance in Mtb has long been assumed to arise mainly by spontaneous mutations in specific genes that are related to the drugs target. In addition, increased efflux pump activity may contribute to unexplained resistance to anti-mycobacterial drugs in the absence of gene mutations known to confer resistance [24].

Although eight of the studied genes, $R v 1410 c$ [4], Rv1456c [25], $R v 1457 c$ [25], Rv1458c [25], Rv1258c [23], Rv1217c [5,22], Rv1819c [26], and $R v 1218 c[5,23]$, have already been reported to be overexpressed in mycobacteria exposed to RIF, the overexpression of $R v 3065, R v 2846, R v 2942$, and $R v 2459$ EPs genes were demonstrated in the present study at $72 \mathrm{~h}$. Overexpression of the Rv3065 ( $\mathrm{mmr}$ ) [6,27,28], Rv1258c (tap-like gene) [23,27,28], Rv1410c (p55) [23,27,28], Rv1819 [26], Rv2459 (jefA) [9,26,27], Rv2942 (mmpL7) $[27,28]$, and $R v 2846 c$ (efpA) [28] genes has also been reported previously in mycobacteria exposed to INH and EMB.

Gupta et al. [29] and Pang et al. [8] did not find significant expression of the Rv3065 in resistant $M t b$ clinical isolates exposed to RIF, as observed in the present study in $M t b \mathrm{H}_{37} \mathrm{Rv}$ at $72 \mathrm{~h}$ of exposure to $0.5 \times$ MIC of RIF. One possible explanation for the difference may be related to the use of clinical isolates, the exposure time and RIF concentration, which were not specified by Gupta et al. [26] or Pang et al. [8].

At 16 and $72 \mathrm{~h}$ of exposure to the RIF + VP combination, six EPs genes (Rv1218, Rv1457, Rv1819, Rv1217, Rv2459, and $R v 1258$ ) and four ( $R v 1457, R v 1258, R v 2846$, and $R v 2942$ ) exhibited significant overexpression $(p \leq 0.01)$, respectively. Notably, at $72 \mathrm{~h}$ a smaller number of genes and lower EPs expression, with the exception of Rv2846, were observed compared with RIF exposure.

Although, the time-kill curve showed decrease in viable cell counts in $M t b \mathrm{H}_{37} \mathrm{Rv}$ exposed to the RIF + VP combination, similar to RIF, the expression study showed an EPs inhibitory effect in the combination exposure, which was more pronounced throughout the time compared to RIF. Based on the obtained results with Mtb $\mathrm{H}_{37} \mathrm{Rv}$, it would be of interest to conduct a study with RIF + VP combination on RIF resistant clinical isolates. Clearly, this study would clarify the possibility of reducing the resistance mediated by EPs in resistant Mtb. This theory is shared by Ramon-Garcia et al. [30] who studied the effect of other EPIs in Mycobacterium fortuitum.

Additionally, it has been observed that EPIs may also block antiTB drug efflux in $M t b$-infected macrophages, leading to an increase in intracellular drug levels and in drug actions on the bacillus [31]. According to Adams et al. [31], VP is perhaps the most promising inhibitor for further evaluation as an adjunctive anti-TB agent, given its ability to reverse macrophage-induced tolerance to RIF. This combination therapy could be a promising alternative for the treatment of patients with MDR-TB, including in TB/HIV coinfection, which is associated with difficult therapeutic management [12].

\section{Conclusions}

The best drug combination against $M t b \mathrm{H}_{37} \mathrm{Rv}$, in the present study, occurred with RIF + VP, which showed changes in the morphology of bacillus consistent with the sum of the changes observed in each drug individually. The downexpression of some EPs related genes by RIF + VP exposure suggests an effective inhibitory activity of VP in Mtb $\mathrm{H}_{37} \mathrm{Rv}$ as observed by EtBr accumulation. Thus, the role of EPs in promoting drug tolerance and the use of EPIs open up a potentially powerful approach, making necessary the continuation more thoroughly of the study of the RIF + VP combination in Mtb using additional concentration and time of exposition.

\section{Acknowledgements}

We would like to thank Vânia Cristina Desoti and Kátia Aparecida Kern Cardoso for their assistant with fluorometry and the electron microscopes.

\section{Funding}

This work was supported by Fundação Araucária.

\section{Competing interests}

None declared.

\section{Ethical approval}

Not required.

\section{References}

[1] WHO. Global tuberculosis report 2013. Geneva: World Health Organization; 2013. <http://www.who.int/tb/publications/global_report/en/>.

[2] da Silva PE, Von Groll A, Martin A, Palomino JC. Efflux as a mechanism for drug resistance in Mycobacterium tuberculosis. FEMS Immunol Med Microbiol 2011;63:1-9.

[3] Calgin MK, Sahin F, Turegun B, Gerceker D, Atasever M, Koksal D, Karasartova D, Kiyan M. Expression analysis of efflux pump genes among drug-susceptible and multidrug-resistant Mycobacterium tuberculosis clinical isolates and reference strains. Diagn Microbiol Infect Dis 2013;76:291-7.

[4] Ramon-Garcia S, Martin C, Thompson CJ, Ainsa JA. Role of the Mycobacterium tuberculosis P55 efflux pump in intrinsic drug resistance, oxidative stress responses, and growth. Antimicrob Agents Chemother 2009;53:3675-82.

[5] de Knegt GJ, Bruning O, ten Kate MT, de Jong M, van Belkum A, Endtz HP, Breit TM, Bakker-Woudenberg IA, de Steenwinkel JE. Rifampicin-induced transcriptome response in rifampicin-resistant Mycobacterium tuberculosis. Tuberculosis (Edinb) 2013;93:96-101.

[6] Rodrigues L, Villellas C, Bailo R, Viveiros M, Ainsa JA. Role of the Mmr efflux pump in drug resistance in Mycobacterium tuberculosis. Antimicrob Agents Chemother 2013;57:751-7.

[7] Pasca MR, Guglierame P, De Rossi E, Zara F, Riccardi G. mmpL7 gene of Mycobacterium tuberculosis is responsible for isoniazid efflux in Mycobacterium smegmatis. Antimicrob Agents Chemother 2005;49:4775-7.

[8] Pang Y, Lu J, Wang Y, Song Y, Wang S, Zhao Y. Study of the rifampin monoresistance mechanism in Mycobacterium tuberculosis. Antimicrob Agents Chemother 2013;57:893-900.

[9] Gupta AK, Reddy VP, Lavania M, Chauhan DS, Venkatesan K, Sharma VD, Tyagi AK, Katoch VM. jefA (Rv2459), a drug efflux gene in Mycobacterium tuberculosis confers resistance to isoniazid \& ethambutol. Indian J Med Res 2010;132:176-88

[10] Zechini B, Versace I. Inhibitors of multidrug resistant efflux systems in bacteria. Recent Pat Antiinfect Drug Discov 2009;4:37-50.

[11] Viveiros M, Martins M, Rodrigues L, Machado D, Couto I, Ainsa J, Amaral L. Inhibitors of mycobacterial efflux pumps as potential boosters for antitubercular drugs. Expert Rev Anti Infect Ther 2012;10:983-98. 
[12] Gupta S, Tyagi S, Almeida DV, Maiga MC, Ammerman NC, Bishai WR. Acceleration of tuberculosis treatment by adjunctive therapy with verapamil as an efflux inhibitor. Am J Respir Crit Care Med 2013;188:600-7.

[13] Palomino JC, Martin A, Camacho M, Guerra H, Swings J, Portaels F. Resazurin microtiter assay plate: simple and inexpensive method for detection of drug resistance in Mycobacterium tuberculosis. Antimicrob Agents Chemother 2002;46:2720-2.

[14] Caleffi-Ferracioli KR, Maltempe FG, Siqueira VL, Cardoso RF. Fast detection of drug interaction in Mycobacterium tuberculosis by a checkerboard resazurin method. Tuberculosis (Edinb) 2013;93:660-3.

[15] Pillai S, Moellering R, Eliopoulos GM. Antimicrobial combinations. 5th ed. New York: Lippincott Williams \& Wilkins; 2005.

[16] Rodrigues L, Sampaio D, Couto I, Machado D, Kern WV, Amaral L, Viveiros M. The role of efflux pumps in macrolide resistance in Mycobacterium avium complex. Int J Antimicrob Agents 2009;34:529-33.

[17] Limoncu MH, Ermertcan S, Erac B, Tasli H. An investigation of the antimicrobial impact of drug combinations against Mycobacterium tuberculosis strains. Turk J Med Sci 2011;41:719-24.

[18] Livak KJ, Schmittgen TD. Analysis of relative gene expression data using realtime quantitative PCR and the 2(-Delta Delta C(T)) method. Methods 2001;25: 402-8.

[19] de Steenwinkel JE, de Knegt GJ, ten Kate MT, van Belkum A, Verbrugh HA, Kremer K, van Soolingen D, Bakker-Woudenberg IA. Time-kill kinetics of anti-tuberculosis drugs, and emergence of resistance, in relation to metabolic activity of Mycobacterium tuberculosis. J Antimicrob Chemother 2010;65: 2582-9.

[20] Dahl JL. Scanning electron microscopy analysis of aged Mycobacterium tuberculosis cells. Can J Microbiol 2005;51:277-81.

[21] Dahl JL. Electron microscopy analysis of Mycobacterium tuberculosis cell division. FEMS Microbiol Lett 2004;240:15-20.

[22] Wang K, Pei H, Huang B, Zhu X, Zhang J, Zhou B, Zhu L, Zhang Y, Zhou FF. The expression of ABC efflux pump, Rv1217c-Rv1218c, and its association with multidrug resistance of Mycobacterium tuberculosis in China. Curr Microbiol 2013;66:222-6.
[23] Jiang X, Zhang W, Zhang Y, Gao F, Lu C, Zhang X, Wang H. Assessment of efflux pump gene expression in a clinical isolate Mycobacterium tuberculosis by realtime reverse transcription PCR. Microb Drug Resist 2008;14:7-11.

[24] Schmalstieg AM, Srivastava S, Belkaya S, Deshpande D, Meek C, Leff R, van Oers NS, Gumbo T. The antibiotic resistance arrow of time: efflux pump induction is a general first step in the evolution of mycobacterial drug resistance. Antimicrob Agents Chemother 2012;56:4806-15.

[25] Hao P, Shi-Liang Z, Ju L, Ya-Xin D, Biao H, Xu W, Min-Tao H, Shou-Gang K, Ke W. The role of ABC efflux pump, Rv1456c-Rv1457c-Rv1458c, from Mycobacterium tuberculosis clinical isolates in China. Folia Microbiol (Praha) 2011;56:549-53.

[26] Gupta AK, Katoch VM, Chauhan DS, Sharma R, Singh M, Venkatesan K, Sharma VD. Microarray analysis of efflux pump genes in multidrug-resistant Mycobacterium tuberculosis during stress induced by common antituberculous drugs. Microb Drug Resist 2010;16:21-8.

[27] Machado D, Couto I, Perdigao I, Rodrigues L, Portugal I, Baptista P, Veigas B, Amaral L, Viveiros M. Contribution of efflux to the emergence of isoniazid and multidrug resistance in Mycobacterium tuberculosis. PLoS One 2012;7:e34538.

[28] Rodrigues L, Machado D, Couto I, Amaral L, Viveiros M. Contribution of efflux activity to isoniazid resistance in the Mycobacterium tuberculosis complex. Infect Genet Evol 2012;12:695-700.

[29] Gupta AK, Chauhan DS, Srivastava K, Das R, Batra S, Mittal M, Goswami P, Singhal N, Sharma VD, Venkatesan K, Hasnain SE, Katoch VM. Estimation of efflux mediated multi-drug resistance and its correlation with expression levels of two major efflux pumps in mycobacteria. J Commun Dis 2006;38: 246-54.

[30] Ramon-Garcia S, Martin C, Ainsa JA, De Rossi E. Characterization of tetracycline resistance mediated by the efflux pump Tap from Mycobacterium fortuitum. J Antimicrob Chemother 2006;57:252-9.

[31] Adams KN, Szumowski JD, Ramakrishnan L. Verapamil, and its metabolite norverapamil, inhibit macrophage-induced, bacterial efflux pump-mediated tolerance to multiple anti-tubercular drugs. J Infect Dis 2014;210(3): 456-66. 